\title{
Hybrid Recommendation System Memanfaatkan Penggalian Frequent Itemset dan Perbandingan Keyword
}

\author{
Wayan Gede Suka Parwita*1 ${ }^{1}$, Edi Winarko ${ }^{2}$ \\ ${ }^{1}$ Prodi S2/S3 Ilmu Komputer, FMIPA UGM, Yoogyakarta \\ ${ }^{2}$ Jurusan Ilmu Komputer dan Elektronika, FMIPA UGM, Yogyakarta \\ e-mail:*11 gede.suka@gmail.com, ${ }^{2}$ ewinarko@ugm.ac.id
}

\begin{abstract}
Abstrak
Recommendation system sering dibangun dengan memanfaatkan data peringkat item dan data identitas pengguna. Data peringkat item merupakan data yang langka pada sistem yang baru dibangun. Sedangkan, pemberian data identitas pada recommendation system dapat menimbulkan kekhawatiran penyalahgunaan data identitas.

Hybrid recommendation system memanfaatkan algoritma penggalian frequent itemset dan perbandingan keyword dapat memberikan daftar rekomendasi tanpa menggunakan data identitas pengguna dan data peringkat item. Penggalian frequent itemset dilakukan menggunakan algoritma FP-Growth. Sedangkan perbandingan keyword dilakukan dengan menghitung similaritas antara dokumen dengan pendekatan cosine similarity.

Hybrid recommendation system memanfaatkan kombinasi penggalian frequent itemset dan perbandingan keyword dapat menghasilkan rekomendasi tanpa menggunakan identitas pengguna dan data peringkat dengan penggunaan ambang batas berupa minimum similarity, minimum support, dan jumlah rekomendasi. Nilai pengujian yaitu precision, recall, F-measure, dan MAP dipengaruhi oleh besarnya nilai ambang batas yang ditetapkan.
\end{abstract}

Kata kunci-Hybrid recommendation system, frequent itemset, cosine similarity.

\section{Abstract}

Recommendation system was commonly built by manipulating item is ranking data and user is identity data. Item ranking data were rarely available on newly constructed system. Whereas, giving identity data to the recommendation system causes concerns about identity data misuse.

Hybrid recommendation system used frequent itemset mining algorithm and keyword comparison, it can provide recommendations without identity data and item ranking data. Frequent itemset mining was done using FP-Gwowth algorithm and keyword comparison with calculating document similarity value using cosine similarity approach.

Hybrid recommendation system with a combination of frequent itemset mining and keywords comparison can give recommendations without using user identity and rating data. Hybrid recommendation system using 3 thresholds ie minimum similarity, minimum support, and number of recommendations. With the testing data used, precision, recall, F-measure, and MAP testing value are influenced by the threshold value.

Keywords - Hybrid recommendation system, frequent itemset, cosine similarity. 


\section{PENDAHULUAN}

$\mathrm{P}$ eningkatan jumlah dokumen ilmiah yang ada menimbulkan kebutuhan akan suatu sistem yang dapat memberikan rekomendasi dokumen ilmiah yang baik. Recommendation system merupakan model aplikasi yang dibangun dari hasil pengamatan terhadap keadaan dan keinginan pengguna [1]. Berbagai metode pendekatan telah diterapkan dan dikembangkan dalam implementasi recommendation system. Selama dekade terakhir ini, recommendation system telah banyak diterapkan dengan berbagai pendekatan baru, baik oleh dunia industri maupun akademis. Pada dunia industri, recommendation system sangat diperlukan terutama pada website ecommerce. Ini ditunjukkan dengan penggunaan recommendation system pada sebagian besar e-commerce web sites yang dimiliki oleh industri. Selain membantu pengguna dalam mencari item yang diinginkan, recommendation system juga dapat meningkatkan penjualan, ketertarikan maupun loyalitas pengguna terhadap suatu item dan juga perusahaan [2].

Metode yang banyak digunakan adalah collaborative filtering dan content-based filtering. Umpan balik yang digunakan pada metode collaborative filtering mengakibatkan sistem dapat memprediksi keinginan pengguna. Sedangkan metode content-based filtering menggunakan konten dari item sehingga dapat memberikan rekomendasi tanpa adanya umpan balik dari pengguna. Akan tetapi, metode collaborative filtering sangat tergantung dengan umpan balik yang diberikan oleh pengguna. Umpan balik berupa peringkat, data transaksi, maupun data identitas yang diberikan oleh pengguna. Tanpa umpan balik, metode collaborative filtering tidak dapat melakukan rekomendasi. Penggunaan data identitas pada metode userbased collaborative filtering juga mengakibatkan pengguna harus terdaftar pada sistem untuk membedakan klasifikasi data yang dikumpulkan dari pengguna. Akan tetapi, pengguna terkadang enggan untuk mendaftar pada sistem karena kekhawatiran terhadap penyalahgunaan data identitas. Di sisi lain, metode content-based memiliki ketergantungan terhadap perbandingan konten maupun atribut antara item.

Fokus utama dari penelitian ini adalah penerapan kombinasi penggalian frequent itemset dan perbandingan keyword dalam menghasilkan rekomendasi dokumen ilmiah. Sebelumnya penelitian tentang hybrid recommendation system [3, 4, 5, 6, 7, 8, 9] dan document recommendation system $[9,10,11]$ telah banyak dilakukan. Akan tetapi, pada beberapa bagian penelitian tersebut berbasis user-based dan item-based collaborative filtering.

\section{METODE PENELITIAN}

Pembangunan recommendation system terbagi menjadi beberapa tahapan proses. Tahaptahap proses tersebut ditunjukkan oleh Gambar 1. Dokumen pdf (Portable Document Format) dikonversi terlebih dahulu ke dalam format txt (text). Dokumen teks diproses pada keyword extraction system untuk memperoleh keyword dokumen. Keyword extraction system melakukan ekstraksi keyword untuk dokumen yang dimasukkan pada sistem sehingga setiap dokumen akan memiliki daftar keyword hasil ekstraksi.

Data transaksi dibentuk saat proses pemilihan dokumen yang dilakukan oleh pengguna. Proses pemilihan adalah saat pengguna melakukan pemilihan dokumen yang ada pada daftar dokumen hasil pencarian atau hasil rekomendasi. Setiap sesi merupakan satu data transaksi. Dalam satu data transaksi, terdapat deret item yang merupakan id dari dokumen. Deret item ini merupakan dokumen-dokumen yang dipilih pada sesi penggunaan sistem. Dengan demikian, walaupun pengguna sama tetapi penggunaan sistem dilakukan pada sesi yang berbeda, maka data pemilihan dokumen tersebut akan dipisahkan. Hal ini dilakukan untuk mengantisipasi proses pemilihan dokumen dengan konten yang berbeda walaupun penggunanya sama. Penggunaan asumsi tersebut mengakibatkan data identitas pengguna dapat diabaikan. Selain menjadi data transaksi, dokumen pilihan pengguna juga menjadi dokumen acuan untuk menentukan daftar data transaksi terseleksi yang digunakan pada proses penggalian frequent itemset.

IJCCS Vol. 9, No. 2, July 2015: $167-176$ 


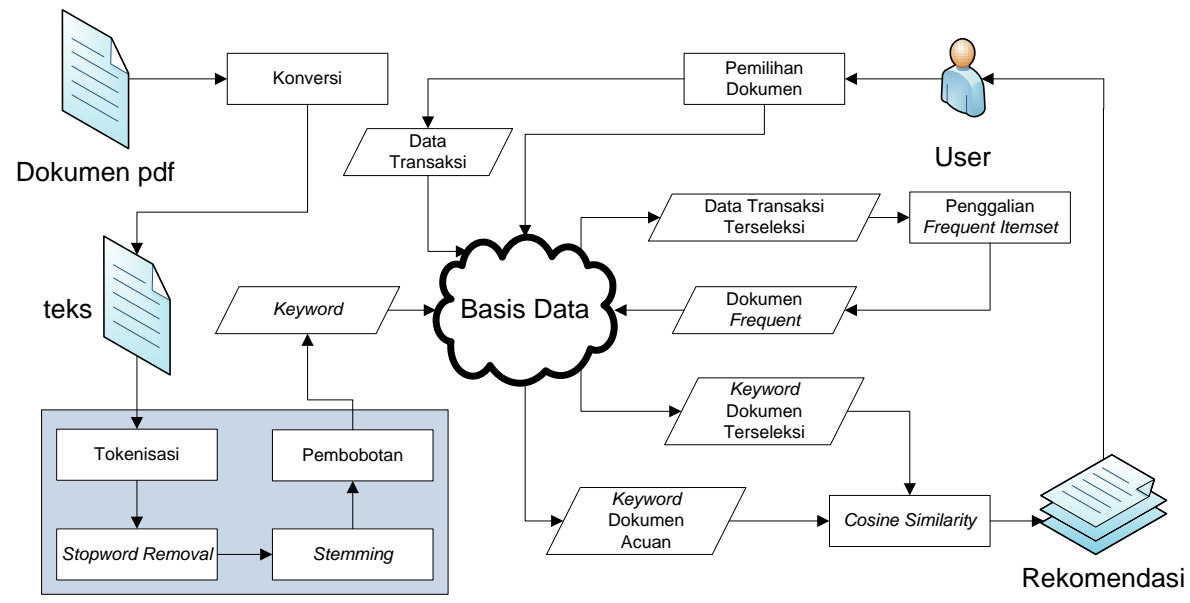

Gambar 1 Arsitektur recommendation system

\subsection{Keyword Extraction System}

Dalam ekstraksi keyword dengan pendekatan tata bahasa berbasis struktur sintaksis, ada beberapa tahap yang dilakukan yaitu tokenisasi, stopword removal, stemming, dan pembobotan kata [12]. Pada tokenisasi dilakukan proses pemecahan deret kata dan penghilangan karakter selain huruf dan angka. Tokenisasi yang digunakan adalah tokenisasi dengan pemisah kata berupa karakter spasi. Daftar kata yang dihasilkan tokenisasi akan diseleksi pada stopword removal. Stopword removal merupakan proses untuk menghilangkan kata yang dianggap tidak penting. Daftar kata yang tidak mengandung stopword lalu diproses pada stemming. Proses stemming merupakan proses untuk mengubah kata turunan menjadi kata dasar. Algoritma stemming yang digunakan adalah algoritma yang dikembangkan di [13]. Daftar kata dasar yang didapatkan pada stemming akan diberikan bobot dengan skema term frequency. Skema term frequency memberikan bobot dengan menghitung jumlah kemunculan kata pada dokumen. Kata dasar beserta bobot yang didapatkan disimpan pada basis data.

\subsection{Penggalian Frequent Itemset}

Penggalian frequent itemset menghasilkan daftar frequent dokumen. Algoritma penggalian frequent itemset yang digunakan adalah algoritma FP-Growth. Dokumen pilihan juga menjadi dokumen acuan yang akan dibandingkan dengan dokumen terseleksi. Dokumen terseleksi untuk perbandingan merupakan frequent dokument dan atau dokumen hasil pencarian. FP-Growth berbasis pada tree disebut dengan FP (Frequent Pattern)-Tree [14]. FP-Tree dapat menghemat penggunaan memori untuk penyimpanan data transaksi. Ide dasar dari FP-Growth dapat digambarkan sebagai skema eliminasi secara rekursif. Dalam langkah preprocessing, dilakukan penghapusan semua item yang kemunculannya kurang dari minimum support yang diberikan. Kemudian dipilih semua transaksi yang mengandung frequent item lalu dibentuk FPTree berdasarkan data transaksi tersebut. Dalam penggalian frequent itemset, dibentuk conditional FP-Tree yang berakhir pada salah satu frequent item. Pembentukan ini dilakukan secara rekursif dengan mengeliminasi satu persatu frequent item akhir yang terdapat pada tree tersebut. Penentuan frequent itemset dilakukan bersamaan saat pengeliminasian dengan melihat support dari frequent item tersebut [15].

\subsection{Perbandingan Keyword}

Keyword dokumen acuan dan keyword dokumen terseleksi dibandingkan dengan menggunakan cosine similarity. Dokumen hasil pencarian akan digunakan apabila penggalian frequent itemset tidak menghasilkan dokumen frequent atau dokumen frequent yang ditemukan tidak dapat memenuhi kebutuhan jumlah rekomendasi. Proses perbandingan dokumen menggunakan cosine similarity menghasilkan nilai similaritas antara dokumen acuan dan dokumen pembanding. Dokumen pembanding akan direkomendasikan kepada pengguna apabila 
nilai similaritas memenuhi ambang batas. Hasil rekomendasi berupa daftar dokumen yang memenuhi ambang batas yang ditentukan oleh pengguna.

\section{HASIL DAN PEMBAHASAN}

Pengujian hybrid recommendation system memanfaatkan penggalian frequent itemset dan perbandingan keyword memerlukan 3 set data yang berupa 100 dokumen ilmiah berbahasa Indonesia, stopword bahasa Indonesia, dan data transaksi untuk melakukan penggalian frequent itemset. Dokumen untuk set data merupakan 95 dokumen ilmiah pada bidang ilmu komputer Prosiding Semantik 2012 dan 5 dokumen ilmiah bidang ilmu komputer Prosiding Senaputro 2012. Untuk rincian dokumen yang digunakan dapat dilihat pada Lampiran 1. Pemilihan dokumen dilakukan agar ektraksi keyword memiliki output dengan kriteria dan bentuk yang sama. Pengujian dilakukan menggunakan minimum similarity $20 \%$ hingga $50 \%$ dan minimum support 5\% hingga 20\% dengan peningkatan setiap 5\%. Jumlah rekomendasi maksimal akan digunakan untuk pengujian precision, recall, F-measure, dan mean average precision. Perhitungan nilai precision juga menggunakan jumlah rekomendasi terbatas. Sistem akan diuji dalam kasus biasa dan juga kasus coldstart.

\subsection{Precision}

Precision pada recommendation system dihitung dengan persamaan (1) [16].

$$
\text { Precision }=\frac{t p}{t p+f p}=\frac{\mid \text { good item recommended } \mid}{\mid \text { all recomendation } \mid}
$$

True positive (tp) pada information retrieval merupakan item relevan yang dihasilkan oleh sistem. Sedangkan false positive (fp) merupakan semua item yang dihasilkan oleh sistem. Tabel 1 menunjukkan adanya peningkatan nilai precision saat nilai minimum support dan minimum similarity ditingkatkan. Peningkatan ini terjadi karena berkurangnya jumlah rekomendasi yang dihasilkan saat nilai ambang batas tersebut ditingkatkan. Nilai precision tertinggi dicapai pada saat minimum support $20 \%$ untuk minimum similarity yang berbeda-beda.

Tabel 1 Nilai precision jumlah rekomendasi maksimal

\begin{tabular}{|c|c|c|c|c|c|c|}
\hline & \multicolumn{4}{|c|}{ Minimum support (\%) } & \multirow{2}{*}{ Coldstart } \\
\hline & & 5 & 10 & 15 & 20 & \\
\hline \multirow{7}{*}{ 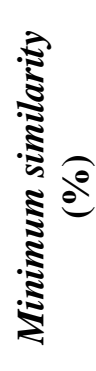 } & 20 & 0.148 & 0.173 & 0.208 & 0.282 & 0.28 \\
\hline & 25 & 0.152 & 0.177 & 0.213 & 0.294 & 0.293 \\
\hline & 30 & 0.17 & 0.181 & 0.218 & 0.306 & 0.306 \\
\hline & 35 & 0.247 & 0.25 & 0.27 & 0.333 & 0.326 \\
\hline & 40 & 0.328 & 0.33 & 0.35 & 0.405 & 0.39 \\
\hline & 45 & 0.439 & 0.439 & 0.444 & 0.467 & 0.458 \\
\hline & 50 & 0.716 & 0.716 & 0.727 & 0.729 & 0.729 \\
\hline
\end{tabular}

Pada kasus coldstart, minimum support tidak mempengaruhi peningkatan atau penurunan nilai precison. Ini disebabkan karena penggalian frequent itemset tidak dapat digunakan saat terjadinya kasus coldstart. Perbedaan nilai precision hanya disebabkan oleh peningkatan minimum similarity. Nilai precision pada kasus coldstart dengan minimum similarity 50\% sama dengan nilai precision kasus biasa dengan minimum support $20 \%$ dan minimum similarity 50\%. Untuk minimum similarity kurang dari $50 \%$, nilai precision pada kasus biasa relatif lebih tinggi dari kasus coldstart saat minimum support kasus biasa sebesar 
20\%. Hal ini disebabkan oleh adanya peningkatan jumlah item hit yang direkomendasikan karena penggalian frequent itemset.

Hasil berbeda terlihat pada pengujian dengan jumlah rekomendasi terbatas. Dengan minimum support 5\% dan 20\%, nilai precision kasus biasa relatif lebih tinggi untuk semua minimum similarity yang digunakan. Hal ini disebabkan karena adanya perbedaan urutan rekomendasi yang didapatkan antara penggalian frequent itemset dan perbandingan dokumen biasa. Selain itu, penggunaan frequent itemset juga mampu menemukan item hit lebih banyak saat dikenakan minimum similarity rendah. Tabel 2 menunjukkan nilai precision jumlah rekomendasi terbatas.

Tabel 2 Nilai precision jumlah rekomendasi terbatas

\begin{tabular}{|c|c|c|c|c|c|c|}
\hline & \multicolumn{4}{|c|}{ Minimum support (\%) } & \multirow{2}{*}{ Coldstar } \\
\hline & & 5 & 10 & 15 & 20 & \\
\hline \multirow{7}{*}{ 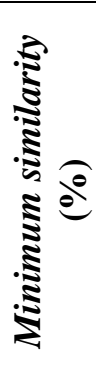 } & 20 & 0.267 & 0.178 & 0.244 & 0.422 & 0.178 \\
\hline & 25 & 0.267 & 0.178 & 0.244 & 0.422 & 0.178 \\
\hline & 30 & 0.267 & 0.178 & 0.244 & 0.422 & 0.2 \\
\hline & 35 & 0.422 & 0.222 & 0.244 & 0.444 & 0.222 \\
\hline & 40 & 0.422 & 0.311 & 0.333 & 0.467 & 0.356 \\
\hline & 45 & 0.444 & 0.333 & 0.333 & 0.467 & 0.422 \\
\hline & 50 & 0.739 & 0.694 & 0.694 & 0.75 & 0.706 \\
\hline
\end{tabular}

Seperti yang terjadi pada jumlah rekomendasi maksimal, nilai precision tertinggi pada jumlah rekomendasi terbatas dicapai pada saat minimum support $20 \%$. Nilai precision kasus biasa pada jumlah rekomendasi terbatas kadang kala lebih tinggi dibandingkan pada rekomendasi maksimal. Akan tetapi, nilai precision kasus coldstart pada rekomendasi terbatas selalu lebih rendah dibandingkan nilai precision kasus coldstart dengan jumlah rekomendasi maksimal.

\subsection{Recall}

Recall digunakan sebagai ukuran dokumen yang relevan yang dihasilkan oleh sistem. Recall untuk evaluasi recommendation system dihitung dengan persamaan (2) [16].

$$
\text { Recall }=\frac{t p}{t p+f n}=\frac{\mid \text { good item recommended } \mid}{\mid \text { all good item } \mid}
$$

False negative (fn) merupakan semua item relevan yang tidak dihasilkan oleh sistem. Nilai recall untuk minimum similarity yang meningkat cenderung menurun pada kasus biasa dan kasus coldstart jumlah rekomendasi maksimal. Hal yang sama terjadi saat minimum support ditingkatkan. Penurunan nilai recall terjadi karena berkurangnya item retrieve yang disertai dengan berkurangnya item hit yang dihasilkan oleh sistem. Dari Tabel 3 dapat dilihat bahwa nilai recall kasus coldstart selalu lebih rendah dari nilai recall kasus biasa untuk penggunaan minimum similarity yang berbeda-beda. Ini menunjukkan bahwa penggalian frequent itemset dapat menemukan item hit yang tidak dapat ditemukan pada saat sistem menggunakan perbandingan keyword saja. 
Tabel 3 Nilai recall jumlah rekmendasi maksimal

\begin{tabular}{|c|c|c|c|c|c|c|}
\hline & \multicolumn{4}{|c|}{ Minimum support (\%) } & \multirow{2}{*}{ Coldstart } \\
\hline & & 5 & 10 & 15 & 20 & \\
\hline \multirow{7}{*}{ 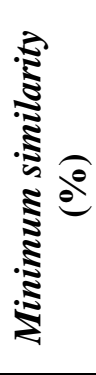 } & 20 & 0.944 & 0.944 & 0.875 & 0.698 & 0.645 \\
\hline & 25 & 0.944 & 0.944 & 0.875 & 0.698 & 0.645 \\
\hline & 30 & 0.944 & 0.944 & 0.875 & 0.698 & 0.645 \\
\hline & 35 & 0.934 & 0.934 & 0.866 & 0.688 & 0.636 \\
\hline & 40 & 0.809 & 0.809 & 0.788 & 0.668 & 0.615 \\
\hline & 45 & 0.635 & 0.635 & 0.615 & 0.555 & 0.535 \\
\hline & 50 & 0.495 & 0.495 & 0.495 & 0.458 & 0.458 \\
\hline
\end{tabular}

Hal sebaliknya terjadi pada nilai recall jumlah rekomendasi terbatas. Peningkatan minimum similarity dan minimum support cenderung meningkatkan nilai recall. Akan tetapi, nilai recall pada minimum support $5 \%$ cenderung lebih tinggi dibandingkan minimum support $10 \%$ dan $15 \%$. Hal ini disebabkan oleh perbedaan hasil frequent itemset yang didapatkan. Di sisi lain, seperti halnya pada jumlah rekomendasi maksimal, nilai recall kasus biasa cenderung lebih tinggi dibandingkan dengan kasus coldstart. Tabel 4 menunjukkan nilai recall jumlah rekomendasi terbatas. Berbeda dengan nilai recall pada jumlah rekomendasi maksimal, nilai recall tertinggi pada jumlah rekomendasi terbatas didapatkan pada saat nilai minimum similarity $50 \%$. Hal tersebut berlaku untuk kasus biasa maupun kasus coldstart.

Tabel 4 Nilai recall jumlah rekomendasi terbatas

\begin{tabular}{|c|c|c|c|c|c|c|}
\hline & \multicolumn{4}{|c|}{ Minimum support (\%) } & \multirow{2}{*}{ Coldstart } \\
\hline & & 5 & 10 & 15 & 20 & \\
\hline \multirow{7}{*}{ 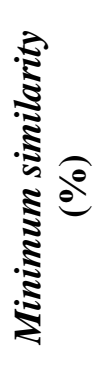 } & 20 & 0.137 & 0.101 & 0.129 & 0.209 & 0.101 \\
\hline & 25 & 0.137 & 0.101 & 0.129 & 0.209 & 0.101 \\
\hline & 30 & 0.137 & 0.101 & 0.129 & 0.209 & 0.11 \\
\hline & 35 & 0.208 & 0.12 & 0.129 & 0.218 & 0.119 \\
\hline & 40 & 0.209 & 0.16 & 0.17 & 0.246 & 0.183 \\
\hline & 45 & 0.22 & 0.172 & 0.171 & 0.245 & 0.255 \\
\hline & 50 & 0.429 & 0.428 & 0.428 & 0.42 & 0.4 \\
\hline
\end{tabular}

\subsection{F-Measure}

F-measure merupakan nilai tunggal hasil kombinasi antara nilai precision dan nilai recall. F-measure dapat digunakan untuk mengukur kinerja dari recommendation system ataupun information retrieval system. Karena merupakan rata-rata harmonis dari precision dan recall, F-measure dapat memberikan penilaian kinerja yang lebih seimbang. Persamaan (3) merupakan persamaan untuk menghitung F-measure [16].

$$
F-\text { Measure }=2 \cdot \frac{\text { precision } \cdot \text { recall }}{\text { precision }+ \text { recall }}
$$

Perhitungan F-measure masing-masing dokumen uji pada kasus biasa ditunjukkan oleh Tabel 5. Hasil perhitungan menunjukkan bahwa untuk minimum similarity dan minimum support yang semakin meningkat, nilai F-measure yang didapatkan juga cenderung meningkat. Peningkatan ini disebabkan oleh meningkatnya nilai precision pada saat dilakukan peningkatan minimum similarity dan minimum support tanpa disertai penurunan nilai recall yang dapat menurunkan nilai F-measure. 
Tabel 5 Nilai F-measure jumlah rekomendasi maksimal

\begin{tabular}{|c|c|c|c|c|c|c|}
\hline & \multicolumn{4}{|c|}{ Minimum support (\%) } & \multirow{2}{*}{ Coldstar } \\
\hline & & 5 & 10 & 15 & 20 & \\
\hline \multirow{7}{*}{ 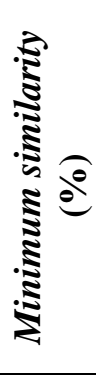 } & 20 & 0.251 & 0.286 & 0.328 & 0.389 & 0.378 \\
\hline & 25 & 0.257 & 0.291 & 0.335 & 0.4 & 0.39 \\
\hline & 30 & 0.282 & 0.298 & 0.341 & 0.41 & 0.401 \\
\hline & 35 & 0.38 & 0.383 & 0.399 & 0.433 & 0.415 \\
\hline & 40 & 0.447 & 0.449 & 0.463 & 0.482 & 0.455 \\
\hline & 45 & 0.481 & 0.481 & 0.478 & 0.481 & 0.466 \\
\hline & 50 & 0.541 & 0.541 & 0.548 & 0.534 & 0.534 \\
\hline
\end{tabular}

Dari Tabel 5 juga dapat dilihat nilai F-measure pada kasus coldstart yang didapatkan oleh sistem yang dibangun. Peningkatan nilai F-measure pada kasus coldstart terjadi saat minimum similarity yang digunakan semakin besar. Nilai F-measure pada kasus biasa saat penggunaan minimum support $20 \%$ cenderung lebih tinggi dibandingkan pada kasus coldstart. Hal ini disebabkan karena nilai precision dan recall kasus biasa jumlah rekomendasi terbatas cenderung lebh tinggi dibandingkan pada kasus coldstart. Untuk jumlah rekomendasi terbatas ditunjukkan oleh Tabel 6.

Tabel 6 Nilai F-measure jumlah rekomendasi terbatas

\begin{tabular}{|c|c|c|c|c|c|c|}
\hline & \multicolumn{4}{|c|}{ Minimum support (\%) } & \multirow{2}{*}{ Coldstart } \\
\hline & & 5 & 10 & 15 & 20 & \\
\hline \multirow{7}{*}{ 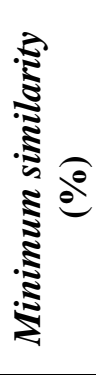 } & 20 & 0.175 & 0.124 & 0.164 & 0.273 & 0.124 \\
\hline & 25 & 0.175 & 0.124 & 0.164 & 0.273 & 0.124 \\
\hline & 30 & 0.175 & 0.124 & 0.164 & 0.273 & 0.137 \\
\hline & 35 & 0.272 & 0.151 & 0.164 & 0.286 & 0.15 \\
\hline & 40 & 0.273 & 0.205 & 0.219 & 0.311 & 0.236 \\
\hline & 45 & 0.288 & 0.221 & 0.22 & 0.31 & 0.299 \\
\hline & 50 & 0.502 & 0.486 & 0.486 & 0.507 & 0.48 \\
\hline
\end{tabular}

Pada jumlah rekomendasi terbatas untuk kedua kasus uji, nilai F-measure yang didapatkan lebih rendah dari jumlah rekomendasi maksimal. Seperti halnya pada jumlah rekomendasi maksimal, nilai F-measure untuk kasus coldstart relatif lebih rendah dari kasus biasa dengan minimum support 20\%. Nilai f-measure tertinggi untuk jumlah rekomenasi maksimal dan jumlah rekomendasi terbatas didapatkan saat penggunaan minimum similarity $50 \%$.

\subsection{Mean Average Precision (MAP)}

Nilai mean average precision (MAP) merupakan nilai rata-rata dari average precision. Average precision merupakan nilai yang didapatkan dari setiap nilai precision item relevan yang dihasilkan dan menggunakan nilai 0 untuk item relevan yang tidak dihasilkan oleh sistem. Nilai precision untuk average precision dihitung dengan memperhatikan urutan item yang diberikan oleh sistem, sehingga nilai precision diberikan untuk setiap item yang dihasilkan oleh sistem. Persamaan (4) merupakan persamaan untuk menghitung nilai mean average precision dalam information retrival [17]. 


$$
\operatorname{MAP}(Q)=\frac{1}{|Q|} \sum_{j=1}^{\mid Q \|} \frac{1}{m_{j}} \sum_{k=1}^{m_{j}} \operatorname{Pecision}\left(R_{j k}\right)
$$

Dimana:

$$
\begin{array}{ll}
\mathrm{Q} & \text { : jumlah query uji } \\
\mathrm{R} & \text { : item relevan yang dihasilkan oleh sistem } \\
\mathrm{m} & \text { : jumlah } \text { item relevan yang dihasilkan dari query }
\end{array}
$$

Dalam penelitian ini, query $(\mathrm{Q})$ merupakan item uji yang digunakan dalam pengujian. Perhitungan mean average precision setiap item uji ditunjukkan oleh Tabel 7. Pengujian dengan penggunaan minimum similarity dan minimum support yang berbeda menunjukkan nilai mean average precision tidak selalu meningkat. Nilai mean average precision maksimal diperoleh saat minimum similarity yang digunakan sebesar 50\% dan minimum support sebesar 5\%. Nilai

\begin{tabular}{|c|c|c|c|c|c|c|}
\hline & \multicolumn{4}{|c|}{ Minimum support (\%) } & \multirow{2}{*}{ Coldstar } \\
\hline & & 5 & 10 & 15 & 20 & \\
\hline \multirow{7}{*}{ 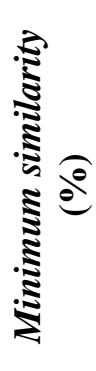 } & 20 & 0.284 & 0.195 & 0.225 & 0.329 & 0.191 \\
\hline & 25 & 0.285 & 0.195 & 0.225 & 0.332 & 0.198 \\
\hline & 30 & 0.29 & 0.196 & 0.226 & 0.335 & 0.205 \\
\hline & 35 & 0.359 & 0.243 & 0.273 & 0.35 & 0.211 \\
\hline & 40 & 0.366 & 0.298 & 0.341 & 0.361 & 0.263 \\
\hline & 45 & 0.323 & 0.304 & 0.306 & 0.3 & 0.281 \\
\hline & 50 & 0.417 & 0.381 & 0.389 & 0.35 & 0.355 \\
\hline
\end{tabular}
mean average precision dengan minimum support 5\% selalu lebih tinggi saat penggunaan minimum similarity lebih besar dari $30 \%$.

Tabel 7 Nilai mean average precision

Nilai mean average precision cenderung selalu meningkat pada saat penggunaan minimum similarity $10 \%$ dan pada kasus coldstart. Selain penggunaan minimum similarity $10 \%$ dan kasus coldstart, nilai mean average precision menurun saat minimum similarity $45 \%$. Penurunan nilai mean average precision saat minimum similarity $45 \%$ lebih disebabkan oleh berkurangnya item hit yang didapatkan oleh sistem.

Pada kasus coldstart, nilai mean average precision cenderung lebih rendah dari kasus biasa untuk semua minimum similarity. Pada pengunaan minimum similarity 50\%, kasus coldstart hanya unggul dari penggunaan minimum support 20\%. Sedangkan pada saat penggunaan minimum support $10 \%$, kasus coldstart hanya unggul pada penggunaan minimum similarity $25 \%$ dan $30 \%$.

\section{KESIMPULAN}

Setelah melakukan pengujian terhadap hybrid recommendation system yang dibangun, maka dapat diperoleh kesimpulan sebagai berikut:

1. Hybrid recommendation system dapat dibangun dengan kombinasi penggalian frequent itemset dan perbandingan similaritas keyword antara dokumen. Penggalian frequent itemset dapat menggunakan algoritma FP-Growth dan similaritas antara dokumen dapat dihitung menggunakan cosine similarity. Ambang batas yang digunakan adalah minimum support, minimum similarity, dan jumlah dokumen yang direkomendasikan.

2. Pada pengujian untuk kasus biasa untuk jumlah rekomendasi maksimal, peningkatan nilai precision dan F-measure terjadi saat minimum similarity dan minimum support ditingkatkkan. Hasil terbaik didapatkan saat minimum support yang digunakan sebesar 
$20 \%$ dan minimum similarity 50\%. Sedangkan nilai recall cenderung menurun saat minimum similarity dan minimum support ditingkatkkan. Hasil terbaik didapatkan pada saat minimum similarity kurang dari $40 \%$ dan minimum support kurang dari $15 \%$. Untuk nilai mean average precision, nilai terbaik didapatkan pada saat minimum support $20 \%$ dan minimum similarity $50 \%$.

3. Untuk rekomendasi terbatas, nilai precision dan F-measure tertinggi didapatkan pada penggunaan minimum support 20\%. Penetapan minimum support yang lebih tinggi, dapat meningkatkan nilai precision dan f-measure. Sedangkan pada nilai recall, nilai tertinggi didapatkan pada penggunaan minimum support $10 \%$. Peningkatan minimum similarity mengakibatkan meningkatnya nilai precision, dan F-measure. Nilai tertinggi pada precision dan F-measure didapatkan pada saat penggunaan minimum similarity $50 \%$ sedangkan pada recall, nilai tertinggi didapatkan pada saat minimum support kurang dari $40 \%$.

4. Nilai pengujian precision, recall, F-measure, dan mean average precision untuk kasus biasa dapat mencapai nilai yang lebih tinggi dibandingkan dengan kasus coldstart baik untuk jumlah rekomendasi terbatas maupun rekomendasi maksimal.

\section{SARAN}

Dari penelitian yang telah dilakukan sistem memiliki kelemahan pada skema stopword. Penerapan skema baru untuk mengatasi perubahan stopword diperlukan karena penambahan dan pengurangan stopword dapat mengakibatkan keyword yang diekstraksi dari dokumen menjadi tidak valid. Penggunaan stopword yang khusus untuk dokumen ilmiah juga dibutuhkan agar stopword yang terdaftar tepat guna sehingga dapat meningkatkan kinerja sistem. Untuk meningkatkan jumlah item relevan, diperlukan kombinasi algoritma lain saat penggalian frequent itemset tidak dapat memenuhi jumlah rekomendasi yang diinginkan. Penggalian frequent itemset membutuhkan waktu yang cukup lama karena adanya pembentukan tree yang berulang-ulang. Penerapan algoritma algoritma incremental untuk penggalian frequent itemset yang dapat mengatasi pengulangan proses penggalian frequent itemset. Pengujian pada penggunaan dokumen uji yang lebih banyak dan bervariasi juga dibutuhkan.

\section{DAFTAR PUSTAKA}

[1] McGinty, L. dan Smyth, B., 2006, Adaptive Selection : An Analysis of Critiquing and Preference-Based Feedback in Conversational Recommender Systems, International Journal of Electronic Commerce, 11, 35-57.

[2] Godfrey, A. L., 2007, A Product Segmentation Approach and its Relationship to Customer Segmentation Approaches and Recommendation System Approaches, Thesis, The University of Texas at Austin.

[3] Chikhaoui, B., Chiazzaro, M., dan Wang, S., 2011, An Improved Hybrid Recommender System by Combining Predictions, Workshops of International Conference on Advanced Information Networking and Applications, 22-25 March 2011, 644-649.

[4] Djamal, R. A., Maharani, W. dan Kurniati, A. P., 2010, Analisis dan Implementasi Metode Item-Based Clustering Hybrid pada Recommender System, Konferensi Nasional Sistem dan Informatika 2010, 13 November 2010, 216-222.

[5] Hayati, N., 2011, Metode Hybrid (Content dan Collaborative Based) Nearest Neighbour Untuk Sistem Rekomendasi Pariwisata, Skripsi, PS. Teknologi Informasi FMIPA USU. 
[6] Hsieh, S. M., Huang, S. J., Hsu, C. C., dan Chang, H. C., 2004, Personal Documents Recommendation System Based on Data Mining Techniques, International Conference on Web Intelligence, 20-24 September 2004, 51-57.

[7] Li, Q. dan Kim, B. M., 2003, Clustering Approach for Hybrid Recommender System, International Conference on Web Intelligence, 13-17 Oktober 2003, 33-38.

[8] Liangxing, Y. dan Aihua, D., 2010, Hybrid Product Recommender System for Apparel Retailing Customers, WASE International Conference on Information Engineering, 14-15 Agustus 2010, 356-360.

[9] Pham, T. V. dan Thach, L. N., 2011, Social-aware Document Similarity Computation for Recommender Systems, Ninth IEEE International Conference on Dependable, Autonomic and Secure Computing, 12-14 Desember 2011, 872-878.

[10] Melamed, D., Shapira, B., dan Elovici, Y., 2007, MarCol: A Market-Based Recommender System, IEEE Intelligent Systems, 22, 74-78.

[11] Popa, H. E., Negru, V., Pop, D., dan Muscalagiu, I., 2008, DL-AgentRecom - A multiagent based recommendation system for scientific documents, International Symposium on Symbolic and Numeric Algorithms for Scientific Computing, 26-29 September 2008, 320324.

[12] Oelze, I., 2009, Automatic Keyword Extraction for Database Search, Ph.D. Thesis, University of Hannover, Hannover.

[13] Tala, F. Z., 2003, A Study of Stemming Effects on Information Retrieval in Bahasa Indonesia, Master Thesis, Universiteit van Amsterdam

[14] Zaki, M.J. dan Meira, W. Jr., 2014, Data Mining and Analysis : Fundamental Concepts and Algorithms, Cambridge University Press, Cambridge.

[15] Han, J., Kamber, M., dan Pei, J., 2011, Data Mining : Concepts and Techniques, Morgan Kaufmann Publisher, San Francisco.

[16] Jannach D., Zanker M., Felfernig, A., dan Friedrich, G., 2010, Recommender Systems an Introduction, Cambridge University Press, Cambridge.

[17] Manning, C. D., Raghavan, P., dan Schütze, H., 2009, An Introduction to Information Retrieval, Cambridge University Press, Cambridge, England. 